ScIDice

\section{Management Of Large Periapical Lesion Using Platelet - Rich Fibrin Mixed With Bone Graft - A Case Reports}

ISSN: $2377-8075$
Case Report

\author{
S Deepak $^{1 *}$, Anjaneyulu $\mathrm{K}^{2}$, MS Nivedhitha ${ }^{3}$ \\ ${ }^{1}$ M.S.Nivedhitha, Department of Conservative Dentistry and Endodontics, Saveetha Dental College and Hospitals, Saveetha Institute of Medical and \\ Technical Sciences, Saveetha University, Chennai, India. \\ ${ }^{2}$ Reader, Department of Conservative Dentistry and Endodontics, Saveetha Dental College and Hospitals, Saveetha Institute of Medical and Techni- \\ cal Sciences, Saveetha University, Chennai, India. \\ ${ }^{3}$ Professor and Head, Department of Conservative Dentistry and Endodontics, Saveetha Dental College and Hospitals, Saveetha Institute of Medical \\ and Technical Sciences, Saveetha University, Chennai, India.
}

\title{
Abstract
}

Dental trauma is one of the factors which is associated with disruption of blood supply to the pulp which is responsible for the occurrence of pulpal necrosis later developing into endodontic infection. Pulpal infection may be immediate or delayed. In young patients with delayed treatment, the pulp may show various alterations like internal resorption, dystrophic calcification, and pulpitis which may change into partial or total necrosis of pulp.

Periapical surgery is required when periradicular pathosis associated with endodontically treated teeth which cannot be resolved by nonsurgical root canal therapy (retreatment), or when retreatment has been unsuccessful, not feasible or contraindicated. Faster the regeneration of bone, better the prognosis. Platelet rich fibrin has many advantages over platelet-rich plasma as it provides a physiologic architecture that is very favorable to the healing process, which is obtained due to the slow polymerization process. Being a rich source of growth factors, platelet rich fibrin (PRF) possess many advantages in bone regeneration.

This case reports shows the successful treatment of a trauma induced large periapical lesion using PRF mixed with bone graft.

Keywords: Periapical Lesion; Bone Graft; Hydroxyapetite.

\section{Introduction}

Dental traumatic injuries usually occur in 7- to 12 -year-old age group and mostly due to falls and accidents near home or school. Anterior region of the mouth is most commonly affected in dental trauma [1]. Dental trauma may affect the teeth and alveolar bone and may involve the pulp and periodontal ligament directly or indirectly [2].

Dental trauma is one of the factors which is associated with disruption of blood supply to the pulp which is responsible for the occurrence of pulpal necrosis later developing into endodontic infection. Pulpal infection may be immediate or delayed. In young patients with delayed treatment, the pulp may show various al- terations like internal resorption, dystrophic calcification, and pulpitis which may change into partial or total necrosis of pulp [3]. Depending on bacterial and host related factors, endodontic infection progresses and perpetuates into acute or chronic apical periodontitis [4]. Especially, the dental traumatic injuries affecting the anterior teeth can result in pain, psychological problems, and disfigurement of the face and the untreated traumatic teeth may develop cyst like apical periodontitis [5]. To manage such cases, periapical surgery of the affected teeth is one of the treatment options. The success rate achieved by traditional means of surgery varies from $40 \%$ to $90 \%$. With the advanced endodontic surgical armamentarium, the success rate increased to $96.8 \%[6]$. Zuolo et al. reported that the postsurgical outcome is $97 \%$ for the anterior teeth and $85 \%$ for the posterior teeth due to complex

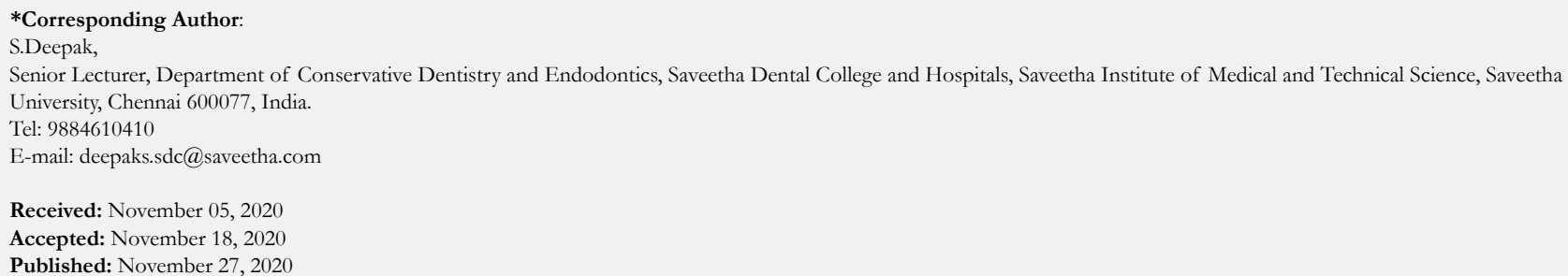

Copyright: S Deepak ${ }^{\circ} 2020$. This is an open-access article distributed under the terms of the Creative Commons Attribution License, which permits unrestricted use, distribution and reproduction in any medium, provided the original author and source are credited. 
radicular anatomy [7].

1990s, with the rapid development of the techniques and equipment, platelet-rich plasma (PRP), which contained a higher concentration of platelets than fibrin glue, was available. The first PRP study in the field of oral surgery was introduced by Whitman et al., in 1997 [8].

Platelet-rich fibrin (PRF) is a modification of PRP. Although introduced a decade ago, it is still used in many medical specialties as well as in oral and maxillofacial surgery. It is indicated for alveolar bone augmentation, sinus lift procedure, extraction socket preservation, defect reconstruction following cyst enucleation or tumor excision, and also alveolar cleft repair. PRF is an autologous fibrin with a large quantity of platelets and leukocyte cytokines [9]. This concentrate contains growth factors like PDGF, TGF, VEGF, IGF, and EGF [10]. These growth factors play a central role in hemostasis and the bone healing process, which makes PRF advantageous. Platelet growth factors are a well-known source of healing cytokines, usable for clinical applications. In many studies, PRF has a direct or indirect effect on bone regeneration in bone grafting or bone defect healing [11-13]. In the literature, authors have reported many advantages of PRF for bone regeneration [14]. There are also many controversies in the literature over the use of different grafts as bone substitutes [15]. The ideal biomaterials should provide osteoconductive and osteoinductive features similar to autogenous bone grafts, which are still considered the gold standard in reconstructive bone surgery.

Demineralized bone matrix (DMBM) Xenograft is a bone inductive sterile bio resorbable material composed of Type I collagen. It is extracted from bovine cortical samples that results in nonimmunogenic flowable particles of approximately $250 \mu \mathrm{m}$ that are completely replaced by host bone in 4-24 weeks. The Xenograft combination for periodontal regeneration therapy results in an interesting and effective clinically useful modality to the clinician in treating various periodontal osseous defect [16].

The ideal outcome of the surgical procedure should be regeneration of the tissues. This can be achieved with the application of guided tissue regeneration (GTR) technique. GTR works on the concept of cell occlusion, by restriction of rapidly proliferating epithelial and gingival cells. This promotes the repopulation of the surgical defect with periodontal ligament cells, which assists in the regeneration of tooth supporting tissues [17]. The principle of GTR can be successfully used, as an adjunctive technique in PR surgery [18-20].

Previously our team had conducted numerous studies which include in vitro studies [21-27] review [28-31], survey [32, 33], clinical trial [34], Case report [35]. This case reports presents the successful treatment of a "trauma induced large periapical lesion in maxillary and mandibular central incisors by surgical endodontic treatment using PRF mixed with bone graft \& GTR"

\section{Case Report 1}

A 35-year-old male patient complains of pain and swelling in the upper front region of mouth for the past 2 weeks. The pain was continuous and throbbing. His medical history was noncontributory. His dental history revealed trauma to lower anterior teeth due to an accident 12 years ago. On clinical examination, 21 was discolored. Soft tissue examination revealed a sinus opening was seen on the labial aspect of maxillary right central incisor. The area was tender on palpation and the teeth were tender on percussion.

On vitality examination, teeth were nonvital. Radiographic examination revealed a large periapical radiolucency associated with 21,22. The periapical lesion associated with 21,22 having regular borders, was seen along the apical and lateral root surfaces of maxillary central incisors. Based on the above clinical and radiographic findings, maxillary central incisors were diagnosed as Non-vital 21,22 with periapical lesion. A combined approach of orthograde endodontic treatment for 21,22 followed by periapical surgery was planned. The patient was informed about the procedure and consent was taken.

Local anesthesia was administered, under rubber dam isolation, and access cavity was done using a number 2 high speed round diamond bur. Working length was determined by apex locator and canal patency was checked with number $15 \mathrm{~K}$-file. Cleaning and shaping of the root canals were performed by hand instruments with step-back technique up to 45 ISO size K-file with alternate irrigation of $3 \%$ sodium hypochlorite $(\mathrm{NaOCl})$ solution and saline. Two percent chlorhexidine ( $\mathrm{CHX}$ ) was used as a final irrigating solution. Calcium hydroxide paste (RC CAL) was given as an intracanal medicament for one week. Patient was prescribed $500 \mathrm{mg}$ of amoxicillin thrice a day for five days, $400 \mathrm{mg}$ of metronidazole thrice a day for 5 days and combination of $100 \mathrm{mg}$ of aceclofenac and $15 \mathrm{mg}$ of serratiopeptidase twice a day for five days. One week later, the patient was asymptomatic \& disappearance of intra oral sinus opening, obturation was done with cold lateral compaction technique in 11,21,22 and the access cavity was restored with composite resin.

Before performing the endodontic surgery, the patient was advised to undergo blood investigations to rule out bleeding disorders. Complete blood picture and coagulation studies report were normal. The general health condition of the patient before the surgery was good and he fell under ASA I, according to the "ASA" physical status classification system.

Under local anesthesia, a full thickness mucoperiosteal flap was elevated. A large soft lesion was seen involving the root apices of 21,22 . The lesion was circumferentially separated from the bony crypt and the Using Graceycurettes, the granulation tissue in the apical and lateral root surfaces of the maxillary central incisors was curetted. For the histopathological examination, the granulation tissue was fixed in 10\% buffered formalin. The surgical site was washed with sterile saline solution after the complete removal of the lesion. Apical $3 \mathrm{~mm}$ of the roots was resected for 21,22 and the retrograde filling was done with mineral trioxide aggregate (MTA).

As the extension of the defect was large, bone graft (Osseograft) mixed with PRF \& GTR was placed in the defect. The mucoperiosteal flap was approximated and sutured in place and immediate periapical radiograph was taken for the confirmation of accuracy of retrograde filling for 21,22. The granulation tissue was sent for histopathological examination, the findings were suggestive of cystic capsule. The patient was periodically reviewed after 6 months. Patient was asymptomatic during 6 months of follow up. 
At 1-year follow-up, a radiograph was taken in relation to maxillary central incisors, which confirmed the satisfactory healing of periapical lesion [Figure $1 \mathrm{~A}-\mathrm{I}]$.

\section{Case Report 2}

A 31-year-old male patient complains of discoloured tooth at the lower front region of mouth. Patient has a history of trauma 5 years back \& started to notice discolouration for the past 2 years with no history of pain \&sensitivity. On clinical examination discolouration and dull pain on palpation in periapical region of 31 .

On vitality testing there was no response in 32,31 and 41. Radiographic examination revealed a large periapical radiolucency associated with $32,31,41$. The periapical lesion having regular borders, was seen along the apical and lateral root surfaces of mandibular central and lateral incisors. With the clinical and radiographic findings, mandibular central incisors was diagnosed as Non-vital 32, $31 \& 41$ with periapical lesion. A combined approach of root canal therapy followed by periapical endodontic surgery was planned. The patient was informed about the procedure and consent was taken.

Local anesthesia was administered, under rubber dam isolation, and access cavity was done using a number 2 high speed round diamond bur. Working length was determined by apex locator and canal patency was checked with number $15 \mathrm{~K}$-file. Cleaning and shaping of the root canals were performed by hand instruments with step-back technique up to 30 ISO size K-file with alternate irrigation of $3 \%$ sodium hypochlorite $(\mathrm{NaOCl})$ solution and saline. Two percent chlorhexidine (CHX) was used as a final irrigating solution. Calcium hydroxide paste (RC CAL) was given as an intracanal medicament for one week. One week later, the patient was asymptomatic \& disappearance of intra oral sinus opening, obturation was done with cold lateral compaction technique in 32, 31, 41 and the access cavity was restored with composite resin. Under local anesthesia, a full thickness mucoperiosteal flap was elevated. A large soft lesion was seen involving the root apices of 32, 31, 41. The lesion was circumferentially separated from the bony crypt and the Using Graceycurettes, the granulation tissue in the apical and lateral root surfaces of the mandibular central incisors was curette. The surgical site was washed with sterile saline solution after the complete removal of the lesion. Apical $3 \mathrm{~mm}$ of the roots was resected for 32, 31 and 41 and the retrograde filling was done with mineral trioxide aggregate (MTA).

As the extension of the defect was large, bone graft (Hydroxyapatite) mixed with PRF was placed in the defect. The mucoperiosteal flap was approximated and sutured in place and the periapical radiograph was taken for the confirmation of accuracy of retrograde filling for 31,32 , and 41 . The patient was periodically reviewed and was asymptomatic during 6 months follow up. [Figure $2 \mathrm{~A}-\mathrm{I}$.

Figure 1. A-Preoperative photograph, B-Preoperative radiograph, C-Obturation using lateral compaction $\&$ entrance filling with light cure composite, D-Curetting the defective areas, E-Retrograde filling using MTA, F-PRF, G-The defective areas were filled using PRF mixed with bonegraft, H-GTR as a membrane, I-1 year follow up.

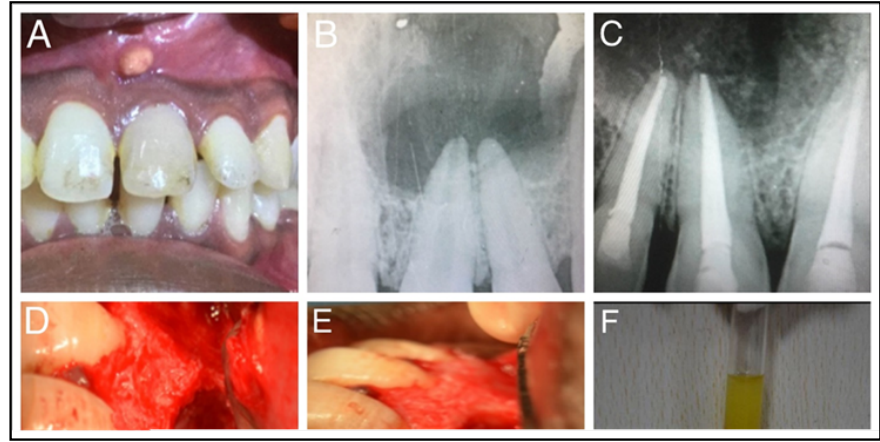

Figure 2. A-Preoperative photograph, B-Preoperative radiograph, C-Obturation using lateral compaction \& entrance filling with light cure composite, D-Curetting the defective areas, E-Apicoectomy, F-Retrograde filling using MTA, G-PRF, H-The defective areas were filled using PRF mixed with bone graft, I-1 year follow up.
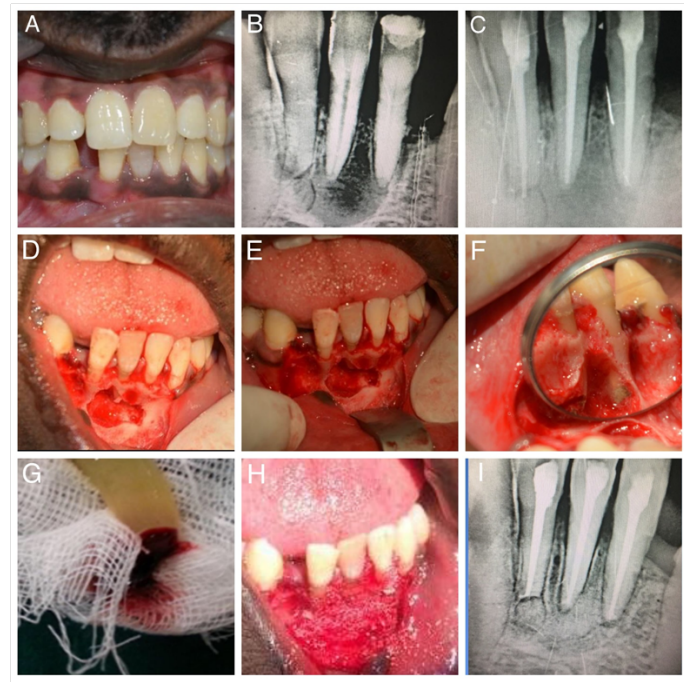


\section{Discussion}

After dental injury, if immediate and appropriate treatment is provided, then it results in successful endodontic outcome. Pulpal response to dental trauma is variable. In some cases, the pulp remains normal, whereas in some cases it becomes necrotic. As a consequence, to dental trauma, the pulp loses its ability to protect itself from bacterial invasion and the bacteria penetrates through the dentinal tubules, colonizes in the necrotic pulp, and leads to the development of periapical lesion [2].

Persistent chronic infection can lead to formation of a periapical cyst. Periapical cysts commonly occur in the mandible and may appear as unilocular or multilocular radiolucency on radiographs. Cystic lesions of the mandible can result in bone remodeling which weakens the bone, leading to functional changes and predisposing the patient to infection and pathologic fracture [36]. Natkin et al. reported that if the radiographic lesion size is 200 $\mathrm{mm} 2$ or larger, then the incidence of cysts was almost $100 \%$ and they have analyzed the data of different studies relating the radiographic lesion size to histology [37].

The indications of periapical endodontic surgery are extruded root filling materials, and lesions after traumatic injuries. Apicoectomy, peri radicular curettage, and root resection are performed during periapical surgery, for achieving successful outcome [38, 39]. In case of nonsurgical endodontic treatment, calcium hydroxide or triple antibiotic paste is kept for a longer duration.

In the present case, MTA was used as a root end filling material during periapical surgery of 21,22. Parirokh and Torabinejad reported that MTA produced cementum formation in $23 \%$ of the specimens after 2-5 weeks of periapical surgery and more than $80 \%$ of root-end filled cavities with MTA showed deposition of cementum 10-18 weeks after surgery. MTA produces favourable results in terms of absence of inflammation, formation of hard tissue and cementum [40].

In this case PRF was mixed with bovine bone graft (osseograft). In an animal study, Lee et al., have demonstrated that clinical outcomes are better using autogenous bone mixed with platelet-enriched fibrin glue than using autogenous bone alone [41]. Tatullo et al,conducted histological and clinical evaluations of 60 patients who underwent surgery before implant surgery [42]. The experimental group received bovine bone graft material combined with PRF, whereas the control group received only bovine bone graft material. The results revealed that PRF led to the production of new bone, even at 106 days. Ozdemir et al. assessed the effects of PRF on bone augmentation in an animal model [43]. PRF and bovine bone showed a greater area of new bone formation than the other two groups at 3 months.

GTR technique successfully used in clinical periodontal practice may be applied as an adjunctive therapy in endodontic surgery. The described case report presents with a large PR lesion from endodontic origin, with no periodontal communication. Several authors have reported the successful resolution of periapical defects with a combined application of GTR and bone grafts [44, 45] or with GTR alone [46, 47] Some have resorted to combined technique of GTR and Platelet rich plasma [48].

\section{Conclusion}

This case report illustrates the "successful management of large periapical lesions of maxillary central incisors with endodontic treatment followed by periapical surgery." The results confirmed satisfactory healing of the large periapical lesion which responded favourably to successful endodontic surgery with combinations of PRF \& BONEGRAFT.

\section{References}

[1]. Skaare AB, Jacobsen I. Dental injuries in Norwegians aged 7-18 years. Dental Traumatology. 2003; 19(2): 67-71.Pubmed PMID: 12656835.

[2]. RE Walton, M Torabinejad. Management of traumatized teeth (3rdedtn). in Principles and Practice of Endodontics. Saunders, Philadelphia, Pa, USA. 2002; 445-465.

[3]. Al-Nazhan S, Andreasen JO, Al-Bawardi S, Al-Rouq S. Evaluation of the effect of delayed management of traumatized permanent teeth. Journal of endodontics. 1995;21(7):391-3.Pubmed PMID: 7499982.

[4]. BergenholtzG.Micro-organisms from necrotic pulp of traumatized teeth. Odontolrevy. 1974; 25(4): 347-58.Pubmed PMID: 4155793.

[5]. Grossman LI. Origin of microorganisms in traumatized, pulpless, sound teeth. Journal of dental research. 1967; 46(3): 551-553.Pubmed PMID: 4961087.

[6]. Kim S, Kratchman S. Modern endodontic surgery concepts and practice: a review. Journal of endodontics. 2006; 32(7): 601-623.Pubmed PMID: 1679366.

[7]. Zuolo ML, Ferreira MOF, Gutmann JL. Prognosis in periradicular surgery: a clinical prospective study. International endodontic journal. 2000; 33(2): 91-98.Pubmed PMID: 11307456.

[8]. Whitman DH, Berry RL, Green DM. Platelet gel: an autologous alternative to fibrin glue with applications in oral and maxillofacial surgery. Journal of oral and maxillofacial surgery. 1997; 55(11): 1294-1299. Pubmed PMID: 9371122 .

[9]. Toffler M, Toscano N, Holtzclaw D, Corso MD, Ehrenfest DD. Introducing Choukroun's platelet rich fibrin (PRF) to the reconstructive surgery milieu. J Implant AdvClin Dent. 2009 Sep; 1(6): 21-30.

[10]. Dohan DM, Choukroun J. PRP, cPRP, PRF, PRG, PRGF, FC... How to find your way in the jungle of platelet concentrates?. Oral Surgery, Oral Medicine, Oral Pathology, Oral Radiology, and Endodontology. 2007 Mar 1;103(3):305-6.

[11]. Kaigler D, Silva EA, Mooney DJ. Guided bone regeneration using injectable vascular endothelial growth factor delivery gel. Journal of periodontology. 2013; 84(2): 230-238.Pubmed PMID: 22668339.

[12]. Panda S, Ramamoorthi S, Jayakumar ND, Sankari M, Varghese SS. Platelet rich fibrin and alloplast in the treatment of intrabony defect. Journal of pharmacy \&bioallied sciences. 2014; 6(2): 127.Pubmed PMID: 24741282.

[13]. Barone A, Ricci M, Romanos GE, Tonelli P, Alfonsi F, Covani U.Buccal bone deficiency in fresh extraction sockets: a prospective single cohort study. Clinical oral implants research. 2015; 26(7): 823-830.Pubmed PMID: 24684275.

[14]. He L, Lin Y, Hu X, Zhang Y, Wu H. A comparative study of platelet-rich fibrin (PRF) and platelet-rich plasma (PRP) on the effect of proliferation and differentiation of rat osteoblasts in vitro. Oral Surgery, Oral Medicine, Oral Pathology, Oral Radiology, and Endodontology. 2009; 108(5): 707713.Pubmed PMID: 19836723.

[15]. Billström GH, Blom AW, Larsson S, Beswick AD. Application of scaffolds for bone regeneration strategies: current trends and future directions. Injury. 2013; 44: S28-S33.Pubmed PMID: 23351866.

[16]. Blumenthal N, Sabet T, Barrington E. Healing responses to grafting of combined collagen: Decalcified bone in periodontal defects in dogs. Journal of Periodontology. 1986; 57(2): 84-90.Pubmed PMID: 3514840.

[17]. Melcher AH. On the repair potential of periodontal tissues. Journal of periodontology. 1976; 47(5): 256-260.Pubmed PMID: 775048.

[18]. Lin YC, Lee YY, Ho YC, Hsieh YC, Lai YL, Lee SY. Treatment of large apical lesions with mucosal fenestration: A clinical study with long-term evaluation. Journal of Endodontics. 2015; 41(4): 563-567.Pubmed PMID: 25576204.

[19]. Lin L, Chen MYH, Ricucci D, Rosenberg PA. Guided tissue regeneration in periapical surgery. Journal of Endodontics. 2010; 36(4): 618-625.Pubmed PMID: 20307733.

[20]. Tsesis I, Rosen E, Tamse A, Taschieri S, Del Fabbro M. Effect of guided 
tissue regeneration on the outcome of surgical endodontic treatment: a systematic review and meta-analysis. Journal of endodontics. 2011; 37(8): 1039-1045.Pubmed PMID: 21763891.

[21]. Rajendran R, Kunjusankaran RN, Sandhya R, Anilkumar A, Santhosh R, Patil SR. Comparative Evaluation of Remineralizing Potential of a Paste Containing Bioactive Glass and a Topical Cream Containing Casein Phosphopeptide-Amorphous Calcium Phosphate: An in Vitro Study. PesquisaBrasileiraemOdontopediatria e ClínicaIntegrada. 2019; 19

[22]. MahalakshmiNandakumar. Comparative evaluation of grape seed and cranberry extracts in preventing enamel erosion: An optical emission spectrometric analysis. Journal of Conservative Dentistry: JCD. 2018; 21(5): 516-520. Pubmed PMID: 30294113

[23]. Siddique R, Sureshbabu NM, Somasundaram J, Jacob B, Selvam D. Qualitative and quantitative analysis of precipitate formation following interaction of chlorhexidine with sodium hypochlorite, neem, and tulsi. Journal of conservative dentistry: JCD. 2019; 22(1): 40-47.Pubmed PMID: 30820081.

[24]. Teja KV, Ramesh S, Priya V. Regulation of matrix metalloproteinase-3 gene expression in inflammation: A molecular study. Journal of conservative dentistry: JCD. 2018; 21(6): 592-596.Pubmed PMID: 30546201.

[25]. Govindaraju L, Neelakantan P, Gutmann JL. Effect of root canal irrigating solutions on the compressive strength of tricalcium silicate cements. Clinical oral investigations. 2017; 21(2): 567-571.Pubmed PMID: 27469101.

[26]. Ramarao S, Sathyanarayanan U. CRA Grid-A preliminary development and calibration of a paper-based objectivization of caries risk assessment in undergraduate dental education. Journal of conservative dentistry: JCD. 2019; 22(2): 185-190.

[27]. Khandelwal A, Palanivelu A. Correlation between dental caries and salivary albumin in adult population in Chennai: An in vivo study. Brazilian Dental Science. 2019; 22(2): 228-233.

[28]. Azeem RA, Sureshbabu NM. Clinical performance of direct versus indirect composite restorations in posterior teeth: A systematic review. Journal of conservative dentistry. JCD. 2018; 21(1): 2-9.Pubmed PMID: 29628639.

[29]. Poorni S, Srinivasan MR, Nivedhitha MS. Probiotic Streptococcus strains in caries prevention: A systematic review. Journal of conservative dentistry: JCD. 2019; 22(2): 123-128.Pubmed PMID: 31142979.

[30]. Siddique R, Nivedhitha MS. Effectiveness of rotary and reciprocating systems on microbial reduction: A systematic review. Journal of conservative dentistry: JCD. 2019; 22(2): 114-122.Pubmed PMID: 31142978.

[31]. Rajakeerthi R, Ms N. Natural Product as the Storage medium for an avulsed tooth-A Systematic Review. Cumhuriyet Dental Journal. 2019;22(2):24956.

[32]. Janani K, Sandhya R. A survey on skills for cone beam computed tomography interpretation among endodontists for endodontic treatment procedure. Indian Journal of Dental Research. 2019; 30(6): 834-838.Pubmed PMID: 31939356.

[33]. Manohar MP, Sharma S. A survey of the knowledge, attitude, and awareness about the principal choice of intracanal medicaments among the general dental practitioners and nonendodontic specialists. Indian Journal of Dental Research. 2018; 29(6): 716-720.Pubmed PMID: 30588997.

[34]. Jenarthanan S, Subbarao C. Comparative evaluation of the efficacy of diclofenac sodium administered using different delivery routes in the management of endodontic pain: A randomized controlled clinical trial. Journal of conservative dentistry: JCD. 2018; 21(3): 297-301.Pubmed PMID: 29899633
[35]. MalliSureshbabu N, Selvarasu K, Nandakumar M, Selvam D. Concentrated growth factors as an ingenious biomaterial in regeneration of bony defects af ter periapical surgery: A report of two cases. Case reports in dentistry. 2019; 2019: 7046203. Pubmed PMID: 30805222.

[36]. Weber AL, Kaneda T, Scrivani SJ, Aziz S. Jaw: cysts, tumors, and nontumorous lesions. Head and neck imaging, 4th edn. Mosby, St. Louis. 2003: 930-94

[37]. Natkin E, Oswald RJ, Carnes LI. The relationship of lesion size to diagnosis, incidence, and treatment of periapical cysts and granulomas. Oral Surgery, Oral Medicine, Oral Pathology. 1984 Jan 1; 57(1): 82-94.

[38]. VonArx T. Failed root canals: the case for apicoectomy (periradicular surgery). Journal of Oral and Maxillofacial Surgery. 2005; 63(6): 832-837.Pubmed PMID: 15944982.

[39]. Gerhards F, Wagner W. Sealing ability of five different retrograde filling materials. Journal of endodontics. 22(9): 463-466.Pubmed PMID: 9198426.

[40]. Parirokh M, Torabinejad M.Mineral trioxide aggregate: a comprehensive literature review-part III: clinical applications, drawbacks, and mechanism of action. Journal of endodontics. 2010; 36(3):400-13.Pubmed PMID: 20171353.

[41]. Lee HJ, Choi BH, Jung JH, Zhu SJ, Lee SH, Huh JY, et al. Maxillary sinus floor augmentation using autogenous bone grafts and platelet-enriched fibrin glue with simultaneous implant placement. Oral Surgery, Oral Medicine, Oral Pathology, Oral Radiology, and Endodontology. 2007; 103(3): 329-333.Pubmed PMID: 17321442.

[42]. Tatullo M, Marrelli M, Cassetta M, Pacifici A, Stefanelli LV, et al. Platelet Rich Fibrin (PRF) in reconstructive surgery of atrophied maxillary bones: clinical and histological evaluations. International journal of medical sciences. 2012; 9(10): 872.Pubmed PMID: 23155361.

[43]. Ozdemir H, Ezirganli S, Kara MI, Mihmanli A, Baris E. Effects of platelet rich fibrin alone used with rigid titanium barrier. Archives of oral biology 2013; 58(5): 537-544.Pubmed PMID: 23141995.

[44]. Taschieri S, Del Fabbro M, Testori T, Saita M, Weinstein R. Efficacy of guided tissue regeneration in the management of through-and-through lesions following surgical endodontics: a preliminary study. International Journal of Periodontics \& Restorative Dentistry. 2008; 28(3): 265-271.Pubmed PMID: 18605602

[45]. Lin GH, Chang LY, Lin WC, Lee SY, Lai YL.Interdisciplinary approach for treating a large through-and-through periapical defect using guided tissue regeneration: a case report. International Journal of Periodontics \& Restorative Dentistry. 2014; 34(1): e1-8. Pubmed PMID: 24396848.

[46]. Pecora G, Kim S, Celletti R, Davarpanah M. The guided tissue regeneration principle in endodontic surgery: one-year postoperative results of large periapical lesions. International endodontic journal. 1995; 28(1): 41-46. Pubmed PMID: 7642328.

[47]. Marín-Botero ML, Domínguez-Mejía JS, Arismendi-Echavarría JA, MesaJaramillo AL, Flórez-Moreno GA, Tobón-Arroyave SI. Healing response of apicomarginal defects to two guided tissue regeneration techniques in periradicular surgery: a double-blind, randomized-clinical trial. International endodontic journal. 2006; 39(5): 368-377.Pubmed PMID: 16640635.

[48]. Goyal B,Tewari S, Duhan J, Sehgal PK. Comparative evaluation of plateletrich plasma and guided tissue regeneration membrane in the healing of apicomarginal defects: a clinical study. Journal of Endodontics. 2011; 37(6): 773-780.Pubmed PMID: 21787487 